Orbis Tertius, vol. XXIV, nº 29, e113, mayo-octubre 2019. ISSN 1851-7811

Universidad Nacional de La Plata

Facultad de Humanidades y Ciencias de la Educación

Centro de Estudios de Teoría y Crítica Literaria

\title{
La Habana: ¿mundo congelado? Entrevista con Dazra Novak
}

\section{Katia Viera}

Universidad Nacional de Córdoba, Argentina

El mundo congelado al que alude el título de esta entrevista, y que es también en su versión en inglés ("Ice world”) un cuento de la narradora Dazra Novak (1978, La Habana, Moscú, Berlín) es, en esta oportunidad, la excusa para conversar sobre literatura joven en Cuba y, en particular, sobre la poética de esta escritora, que suele incluirse (o excluirse, según el caso del crítico que haga el recuento, o de la propia voluntad de la narradora) en (de) la lista de nombres de la llamada Generación Año Cero. Actualmente, es una de las narradoras menos atendidas por la crítica en Cuba y que, sin embargo, posee una fructífera producción para pensar en los nuevos modos de acercarse al cuerpo citadino habanero, y a temas que vuelven una y otra vez en las historias de la literatura cubana: el exilio, la isla, el mar, el cuerpo. Sus textos desmontan las recientes afirmaciones (en ocasiones muy rotundas) de que los “jóvenes" escritores cubanos intentan eludir el contexto de su país o ciudad. Su producción escritural no parece prescindir de Cuba ni de La Habana: estos espacios constituyen referentes altamente simbólicos para ficcionalizar nociones tan universales como el sexo y la sexualidad, el amor, la nostalgia o la migración. De esta forma, su obra es parte del conjunto (variado) de textos que complejizan el abierto y problemático perfil de la literatura joven que se escribe actualmente en Cuba.

\section{NOTA BIOGRÁfICO-EDITORIAL}

Dazra Novak (La Habana, Moscú, Berlín, 1978). Narradora. Licenciada en Historia por la Universidad de La Habana. Egresada del Centro de Formación Literaria Onelio Jorge Cardoso. Premio Pinos Nuevos 2007 por el libro Cuerpo Reservado (Cuento, Editorial Letras Cubanas, 2007). Premio David y Premio Especial Cabeza de Zanahoria 2007 por el libro Cuerpo Público (Cuento, Ediciones UNIÓN, 2008). Premio UNEAC de novela Cirilo Villaverde 2011 por Making of (Ediciones UNIÓN, 2012). Cuentos suyos aparecen en numerosas antologías, entre ellas: Como raíles de punta (Ediciones Sed de Belleza, 2013, selección, prólogo y notas de Caridad Tamayo Fernández), Hasta Feldading no paro y otros relatos (Premio Iberoamericano de cuento Julio Cortázar, Editorial Letras Cubanas, 2011) o Ladrón de niños y otros relatos (Premio Iberoamericano de cuento Julio Cortázar, Editorial Letras Cubanas, 2012). Es autora del blog Habana por dentro https://habanapordentro.wordpress.com y columnista de la revista digital Oncuba en la sección "El barrio de Fulanito" http://oncubamagazine.com/category/columnas/el-barrio-de-fulanito/ . Colaboró con la desaparecida Cuba Contemporánea y con la revista Cubahora en las respectivas secciones personales "Letra de molde" y "Una palabra" http://www.cubahora.cu/blogs/una-palabra. Recientemente ha publicado la colección de cuentos Los despreciados (Ediciones Isla de Libros, 2019) y en proceso editorial se encuentran: Habana por dentro (Editorial Casa de las Américas), que constituye una selección de textos de su blog personal, y la novela Niñas en la casa vieja (Editorial Letras Cubanas). 


\section{ENTREVISTA}

KV: Leo en el cuento que comenté al inicio de este texto, la representación de una imagen estática de la ciudad habanera que permite, por un lado, distinguir aquellos semas asociados con la ruina y el desencanto, tales como: la arquitectura derruida por completo, las calles viejas, el agua estancada, los carteles viejos, las viejas en la bodega, "tanta gente, tantas voces y tanta muerte"; pero por otro lado, a la par de este discurso que alude a la decadencia humana y citadina, está colocado otro, que establece una especie de reconciliación con la ciudad, la gente y uno mismo, en un canto que reza: "quiéreme mucho, dulce amor mío, [¿dulce ciudad mía?] que amante siempre te adoraré”. ¿Crees, a propósito de mi percepción anterior, que estableces alguna instancia bisagra entre modos de escribir de generaciones anteriores y otros, de una nueva generación?

DN: Algo parecido a eso es lo que intento. Aunque no sé si esa instancia bisagra responde a "modos" de escribir (eso está por demostrarse). Quizás (ahora que me haces reflexionar sobre algo que no me había pensado de ese modo) es una toma de nota de este estado común a mi generación, esa (in)acción que padecemos humanamente "enmarcada" en un texto literario. Históricamente hablando, donde unos vivieron la realidad nueva, algunos el cenit de esta y otros esa misma realidad en picada, a nosotros ni siquiera nos tocó el punto más bajo. Vivimos de corrido el día que siguió al ya-no-más, lo miramos todo desde el suelo y entre escombros. Entonces no sé si es esta aclaración lo que hago en este tipo de ficciones a lo Ice world, o una justificación, o simplemente revisito ese estado para señalar su peor consecuencia: nuestra parálisis, esa especie de ceguera que nos gana la partida cuando estamos buscando algo importante en un cuarto muy desordenado. Algo importante que está justo delante de nuestros ojos y, sin embargo, no lo vemos, porque todo está movido de lugar -o todavía no se le ha otorgado un lugar como es debido-. Esa instancia bisagra, ante todo, intenta aguzar la mirada, cambiar la perspectiva para volver a encontrar lo importante que sin duda alguna se nos ha perdido.

KV: Tus textos, Cuerpo reservado (2008), Cuerpo público (2009) y Making of (2012), (merecedores de premios nacionales) constituyen un ejemplo de algunas ideas que he defendido en los últimos tiempos y que tiene que ver con la noción de que aunque los textos de la narrativa joven cubana pretendan eludir el contexto de lo cubano siempre se dialoga con él, aunque ese diálogo implique una contracara de lo que venían haciendo los narradores más consagrados en el interior de la Isla. ¿Cómo entiendes tu obra en medio de esto que es para mí ese diálogo en negativo con el "Factor Cuba"?

DN: Esa elusión es una ilusión si reconocemos que el rechazo es también una forma de diálogo. Lo que uno es está irremediablemente atravesado, entre otras tantas cosas, por la ciudad que se habita y sus circunstancias, por el propio momento histórico. Nadie está ajeno a ello, le guste o no. Eso, por supuesto, sale a flote en la escritura. Porque uno, más que cuento, novela o poesía, más que temas, géneros, intenciones o estilos, escribe de lo que uno es y de lo que ha vivido o piensa (la literatura no es solo el tema, sino también la manera en que abordamos ambos, tema y literatura). Claro que en algunas obras será más difícil de decodificar que en otras, los rastros están más o menos disimulados, pero están. En la mía es bastante explícito ese diálogo con el factor Cuba, (Caridad Tamayo lo ha mencionado, como haces tú, en su prólogo de la antología Como raíles de punta), lo que quizá desmienta un poco la teoría de que la joven literatura le da la espalda a la realidad social de hoy en nuestro país.

KV: Roland Barthes escribió que "la ciudad es un discurso, y este discurso es verdaderamente un lenguaje". Observo en el conjunto de tu obra (ficcional y de textos más cercanos al periodismo, la apuesta a la non-fiction) una insistencia por (re)correr La Habana. Este recorrido que es panorama y también corrimiento, desplazamiento de una ciudad, marca tu producción artística. ¿Por qué un discurso de, con, sobre y para La Habana?

DN: Yo tengo una relación especial con mi ciudad. Algo que no sé explicar totalmente y cuyas verdaderas raíces desconozco. Como te comentaba en aquel café en que nos encontramos, creo que soy un alma vieja. Es la única explicación que le encuentro a la nostalgia que siento por tiempos que no viví. Toda esa sonoridad 
de los tiempos del filin y del grupo de experimentación sonora, por ejemplo, despiertan en mí sensaciones de melancolía. Algo que, sumado a esta saudade por una ciudad que tampoco habité en sus tiempos de esplendor, hacen que yo viva en un constante diálogo con lo que fue y lo que no fue, con lo que pudo haber sido y lo que es hoy. Me llama poderosamente la atención esta convivencia mágicopoética de lo destruido y lo que se sostiene y recicla, la forma en que la gente se apropia de ello y lo reproduce, a veces para bien, a veces para mal. La Habana es la metáfora perfecta de esta unión de melancolía y nostalgia, mi nostalcolía.

KV: Leyendo tus textos se me presentan como pequeñas escenas cinematográficas y noto en ellos el trabajo con la luz, e incluso con los olores; no así con los sonidos, elemento tan difícil de integrar al texto escrito. Hace muy poco conversábamos sobre lo importante que es para ti el sonido, ¿por qué y cómo crees que puede integrarse a tu producción artística?

DN. El sonido está, pero es más difícil reconocerlo. Yo lo primero que escribí fueron poemas con rima. Y más tarde, para escribir narrativa, tuve que luchar -y muy duro-, contra esa rima. Hay palabras que están elegidas por el sonido al leerlas - repetición de letras, eses, vocales, algunas cacofonías adorablemente musicales-. La escritura para mí tiene melodía más que respiración, y digamos que un tempo que es el que marca la velocidad de lo que voy contando o describiendo. Si "no me suena", entonces no va. Puedo pasarme bastante rato arreglando una oración, un párrafo, una palabra que no encuentro porque la que está disponible no tiene la cantidad de sílabas o vocales que necesito para articular la frase o figura como corresponde, para que la respiración haga su aporte a la lectura. Hay pequeños juegos traviesos en el texto, pero no sé si alguien a estas alturas los habrá disfrutado tanto como yo al escribirlos. En los textos de mi blog Habana por dentro abordo el sonido desde la música, los ruidos de la ciudad (pregones, llamados a gritos, el sonido de las fichas de dominó sobre una mesa en plena calle), entre otros. En mis textos impresos no lo había usado, como tema quiero decir, hasta esta novela que está por salir Niñas en la casa vieja, cuyo personaje principal es una locutora de radio. Ah, mira, la radio y la madrugada, otra combinación que hace detonar esa nostalcolía que mencioné anteriormente...

KV: En tu obra advierto una subliminal sistematización de lo cursi desde, por ejemplo, el abordaje de lo musical o lo erótico-corporal, para con ello lograr sentidos que no se perciban como cursis. Creo, de modo general, que es un recurso que has logrado defender muy bien desde el punto de vista técnico. Quien te lee en esos textos es capaz de sobrellevar la perturbación "cursi” y traspasar el relato viéndolo desde otra dimensión. ¿Por qué esta exploración de lo cursi en tu literatura?

DN: Más que sobrellevar la "perturbación", hay muchos que se entregan voluntariamente (esta afirmación sale de comentarios de algunos de mis lectores). Lo cursi, o más bien las reacciones de la gente ante lo cursi,es algo que siempre me ha intrigado. Se le trata con desdén, se le evita por todos los medios como si fuera el más grande de todos los pecados. Y de todos modos, querámoslo o no, todos pasamos por lo cursi en diferentes momentos de la vida. ¿Quién no se ha emocionado con un tema musical que marcó un recuerdo romántico? ¿Hay alguien a salvo de una dedicatoria rayana en la cursilería? ¿Cuántos poemas echados a la basura? ¿Cuántos de ellos lamentamos haber escrito después de entregados? Y es que lo cursi como lo vulgar- también tiene gradaciones. Puede ser pedestre, manido, insulso, o comulgar con lo llamado "cheo" entre cubanos. Pero también puede ser pintoresco, divertido, ingenioso. Lo cursi sale a flote, como un corcho, disfrazado hasta entre las posturas más rebuscadas. Y en cualquiera de esos casos, estará invariablemente unido a la emoción. Es en esa unión donde se convierte en todo un desafío: ¿cómo narrar lo cursi sin lucir cursi? ¿Cómo llevarte desde la lectura a experimentar lo cursi que no te permites frente a los otros? Supongo que la lectura, por personal y solitaria, juega a mi favor en este acuerdo tácito que tranquiliza: no te preocupes, querido lector/a, estás a salvo. Nadie se va a enterar de cómo te abandonas al humano terreno de lo cursi.

KV: Percibo, en medio de tanto desorden, caos, fragmentariedad y esquizofrenia de los textos contemporáneos, que tus relatos apuntan, de modo general, hacia una historia bien acotada, y es algo que me inquieta en el extenso marco de las literaturas latinoamericanas del presente. Hoy, ¿sigue siendo para ti un reto salvar la historia, entendida esta en su costado más estructuralista-narratológico? 
DN. Para mí es importante la historia. Creo que estos tiempos de experimentación han dado pie, con excepción de algunos juegos formales realmente valiosos, al facilismo. Se desprecia la historia en pos de narrar un caos vacío y anodino que, es cierto, también forma parte de la vida, pero pasa de largo y nos deja con las manos vacías (y para mí la literatura debe dejar algún rastro). Es como una de esas tardes en que uno mata el tiempo con cualquier cosa y días después, si te preguntan, no sabes qué responder porque es imposible recordar cómo, con qué se lo mató. Contar una historia es lo más difícil. Salir desde el punto A y llegar al punto $\mathrm{B}, \mathrm{C}$ o D, siendo/sintiendo otra cosa. En mi caso es un reto que se bifurca. Por un lado, lograr que la historia y los personajes fluyan, respiren, cuenten, vivan intensamente ese tránsito. Por el otro está la complicidad y/o la emoción del lector saliendo desde el punto A y llegando al punto $\mathrm{B}, \mathrm{C}$ o D, desde sus propias experiencias, desde sus propias historias. Lo explico más claramente: Con mi libro de cuentos Cuerpo público me pasó que dos lectores, una señora de ochenta años y un hombre de unos treinta y tantos, me confesaron más o menos lo mismo: se habían sentido respectivamente jóvenes otra vez. Al tiempo que iban leyendo "mi" ficción, iban revisitando momentos y sensaciones que se les habían quedado en el olvido. Está claro que una parte de esa juventud la escribí yo, pero la otra, la que yo no podré leer, la escribieron ellos.

KV “Todo en la ciudad se juega en los bordes, las franjas, los márgenes de todas esas entidades definibles [...] Tal es el arte de la ciudad: incoativo por esencia y por excelencia. Arte de acercamientos furtivos, arte de pasajes pasajeros, de paseantes insignificantes, de significancias infraleves, expedidas tan pronto como bosquejadas". Este fragmento de Jean-Luc Nancy me lleva hacia tu blog Habana por dentro. Espacio este que, como certeramente has apuntado, resulta ser un recorrido de ciudad. En cierta entrevista que te hicieron decías que no lo consideras como literatura porque no te lo habías planteado como "algo demasiado cargante de significados, demasiado pesado de digerir". A la luz de lo que esbozaba Nancy y muy relacionado con la cita de Barthes de mi segunda pregunta, ¿no crees que esos enlaces entre fotografía, relato (ficcional), documentos, mínimas historias idiosincráticas, costumbristas, ofrecen sí, un texto sobre la ciudad que termina siendo literatura y lenguaje?

DN: Como aquella tarde en el café, una vez más, te digo: válido el regaño. Supongo que eso se desprende de esta resistencia (pensamiento analógico) que ofrecemos a tomar Internet y sus dinámicas como algo tan serio como la letra impresa. El tiempo (activo) de vida de los contenidos en la nube es tan efímero (si bien pueden reciclarse, a veces hasta por obra y gracia del mismísimo azar), que uno se lo toma ligeramente desde su concepción y maneras de replicarlo más tarde en redes sociales. Por otro lado, en mi caso particular, comencé con esta intención de contar con la misma sinceridad y soltura con que se escribe un diario (atributo por excelencia del blog frente a sitios web y otras plataformas), y bueno, está claro que en un diario uno se permite ciertas licencias/ligerezas (escritura de pensamiento, términos coloquiales o íntimos, bad writing) que en otras partes no. Después todo fue cambiando como si fuera un work in progress. Yo no me había probado antes tras el visor de una cámara y, de tanto insistir, se ha dado un tercer producto: binomio imagen/ texto con una lectura otra. El público meta también cambió. Nunca pensé que cubanos dentro de Cuba lo consumieran y mucho menos que extranjeros lo tomaran como "guía alternativa" para conocer nuestro país, costumbres, lenguaje e idiosincrasia. Como si esto fuera poco, ahora salta al impreso en una selección de textos que publicará la editorial de la Casa de las Américas. Todo esto ha provocado una reformulación progresiva de esa dinámica inicial y sí, hoy puedo reconocer que también es literatura y lenguaje.

KV: En medio de un mundo altamente globalizado, para nada estático (nada Ice world), marcado por los gustos de editores y por el prurito de algunos escritores de publicar en grandes editoriales, ¿cómo percibes "escribir con honestidad"?

DN: Escribir desde lo que uno es y desde lo que uno piensa sin dejarse arrastrar por las modas, tendencias, por los "temas que venden". Desconfío de los temas que venden porque pueden convertir a un autor talentoso en una marioneta, cosa muy triste en verdad. Es cierto que a veces toca hacerle guiños al mercado en pos de la necesaria promoción, pero hasta para eso hay estrategias acordes a la dinámica propia, al estilo, a la intención. Con esto quiero decir que si se asume como un reto, pueden salir cosas realmente buenas sin dejar de ser uno 
mismo. En mi caso tengo muy claras las concesiones que jamás haría. Escribir con honestidad, en mi caso, es escribir desde el universo propio de Dazra Novak.

KV: Cuando te hacen una entrevista e incluso en algunos esporádicos textos críticos sobre tu obra, quien escribe pregunta por Dazra, por sus re(s)tos, sus exigencias, sus reescrituras. En un acto puramente estético y también privado, no me es particularmente atractivo develar tu nombre (porque ya es en verdad, Dazra Novak); sin embargo, me resulta inquietante esas ciudades en las que has nacido, ese país que no existe (RDA), porque entiendo allí un diálogo muy estrecho y desgarrador entre la pertenencia de origen a un país inexistente con otro que está en pie, aún. Ello me lleva a pensar en ese proceso de reinventarte (y de reinventar tus textos) siempre como dentro y fuera de un lugar, en una especie de entre-lugar. ¿Consideras que este sea el único modo de trascender estética, literaria y humanamente?

DN: No, no es el único. Pero sí es el que, por dinámico, quiero pensar que exige una lectura más activa. Ubicarse en el no-lugar exige pensarse lo que uno realmente es, lo que uno desea ser: ¿Soy el resultado pasivo de mi circunstancia o realmente soy? Cada situación, por pequeña que sea, puede llegar a tener tantas versiones y variantes como personas hay, y yo noto que nos quedamos tan pasivamente en esa lectura primera -cómoda, pero tan sosa en su literalidad- que no me extraña que el mundo camine hacia su propia destrucción, que la gente esté cada vez más sola/aburrida/inactiva en tiempos cada vez más conectados. Se confunde, tanto en la literatura como en la vida, el movimiento con la acción. Y eso ocurre, pensando a grandes rasgos, porque damos por sentado todo lo que nos cuentan, y peor aún, lo repetimos. Y yo, en mi intento de romper la frontera de esa inercia trato de que mi lector reincidente sepa que no debe buscar siempre lo mismo en mis textos. A mí me sirve más su complicidad, su reescritura, su incomodidad y, por qué no, hasta su posible rechazo. Frente a mis textos siempre podrán elegir si se quedan o se van. Ese entre-lugar que mencionas no es más que una performance, una declaración. Sería muy saludable para estos tiempos si, además de ciudadanos de nuestros respectivos países, comenzáramos a sentirnos ciudadanos del mundo. 